\title{
Estudo da viabilidade da produção de blocos com utilização de resíduo de serragem de rochas ornamentais para alvenaria de vedação
}

\section{Feasibility study of the production of mansory blocks with use of dimension stone sawing dust}

\begin{abstract}
Washington Almeida Moura
Dr., Professor do Programa de Pós-Graduação em Engenharia Civil e Ambiental, Departamento de Tecnologia, Universidade Estadual de Feira de Santana

wam@uefs.br
\end{abstract}

\section{Mônica Batista Leite}

Dra., Professora do Programa

de Pós-Graduação em Engenharia Civil e

Ambiental, Departamento de Tecnologia,

Universidade Estadual de Feira de Santana

mleite.uefs@gmail.com

\section{Resumo}

O Brasil é o quinto produtor de rochas ornamentais no mundo, tendo os Estados do Espírito Santo, Bahia, Ceará e Paraíba como maiores produtores. Nesse setor, a geração de resíduo durante o beneficiamento é bastante significativa. Considerando que a produção de rochas ornamentais em 2004 foi de 6.450 .000 toneladas, o volume estimado de resíduos nas etapas do beneficiamento é de 1.610.000t/ano (Chiodi Filho, 2005). Atualmente esse resíduo vem sendo depositado no pátio das empresas, o que implica custo para as mesmas. De modo geral, a geração de resíduos sólidos tem sido um dos grandes problemas enfrentados pelas indústrias nacionais e internacionais, sobretudo no que se refere ao descarte e manuseio adequados destes resíduos, por ser, geralmente, custoso e de difícil implementação. Nesse estudo, avalia-se a viabilidade de utilização do resíduo de serragem de rochas ornamentais (RSRO), na produção de blocos pré-moldadoss para alvenaria de vedação. O RSRO foi utilizado em substituição parcial do cimento, nos teores de 5\%,10\% e 15\%, em massa. Os blocos produzidos foram avaliados quanto à resistência à compressão e à absorção. Os resultados apontam para a viabilidade da utilização do RSRO como substituição parcial do cimento.

Palavras-chave: Resíduo de serragem de rochas ornamentais, alvenaria de vedação, granito, mármore.

\begin{abstract}
Brazil is the fifth largest producer of dimension stones in the world, and the states of Espirito Santo, Babia, Ceará e Paraíba are the major producers in this country. In this sector, the generation of waste during processing is quite significant. When the production of dimension stones in 2004 was 6,450,000 tons, the estimated volume of waste at the processing stages was 1.610.000t/year (Chiodi Filho, 2005). Currently, this waste has been deposited in the land of the companies, which implies a cost to them. In general, the generation of solid waste has been one of the major problems faced by national and international industries. Especially in regards to the disposal and handling of these wastes because they are generally expensive and difficult to implement. In this study, we assess the feasibility of using waste dimension stone sawing dust (DSSD) in pre-cast blocks for masonry. The DSSD was used to partially replace cement in the contents of $5 \%, 10 \%$ and $15 \%$ by weight. The blocks produced were evaluated for compressive strength and absorption. The results show's viability for the use of DSSD as partial replacement of cement.
\end{abstract}

Keywords: Dimension stone sawing dust, mansory blocks, marble, granite. 


\section{Introdução}

O segmento de rochas ornamentais é bastante significativo na economia brasileira. Abriga todas as atividades da cadeia produtiva principal: jazidas dos mais diferentes tipos de mármores e granitos, empresas para beneficiamento primário (desdobramento) e secundário (polimento e produtos acabados), além de todas as atividades da cadeia de apoio, que incluem fabricantes de máquinas $\mathrm{e}$ equipamentos, fabricantes de insumos industriais, prestadores de serviços técnicos e administrativos, centro de tecnologia (CETEMAG), sindicatos e associações.

No processo de beneficiamento de rochas ornamentais, é gerado grande volume de resíduos. O resíduo gerado pode ser oriundo da extração do bloco, da serragem para enquadrá-los nas dimensões padronizadas, do processo de corte e de polimento, além dos finos da lavra e do beneficiamento. Na serragem, cerca de $20 \%$ a $30 \%$ do bloco é transformado em pó, que é colocado nos pátios das empresas.

No Brasil, a quantidade estimada de a geração desse resíduo fino é de 800.000t/ano. Espírito Santo, Bahia, Ceará e Paraíba são os Estados que mais geram esse resíduo (Chiodi Filho, 2005).

A produção mundial de rochas ornamentais em 2003 foi de cerca 65 milhões de toneladas. O Brasil é um dos maiores produtores do mundo, ocupando a $7^{a}$ posição, com 4,33 milhões de toneladas em 2004 (Guerra, 2005). Entretanto a produção real apresentada pela Associação Brasileira da Indústria de Rochas Ornamentais (ABIROCHAS) foi de 65 milhões de toneladas (Chiodi Filho, 2005).

Existem, no Brasil, 12.000 empresas integradas na cadeia produtiva de rochas, gerando cerca de 125.000 empregos diretos. Essas empresas estão distribuídas em 10 Estados, envolvendo 80 municípios (Chiodi Filho, 2005). As rochas ornamentais extraídas, em forma de matacões, são transportadas até as serrarias para o desdobramento ou serragem (processo de transformação dos blocos em chapas ou placas semi-acabadas, de espessuras que variam de $1 \mathrm{a} 3 \mathrm{~cm}$, utilizando máquinas denominadas de teares).

A serragem dos blocos para obtenção das chapas pode ser feita através de fio diamantado ou utilizando polpa abrasiva. A grande maioria das serrarias utiliza polpa abrasiva no corte, que tem como principais objetivos: lubrificar e resfriar as lâminas, evitar a oxidação das chapas, servir de veículo ao abrasivo e limpar os canais entre as chapas.

A polpa é composta por água, granalha (aço), cal e rocha moída. Geralmente a polpa é distribuída por chuveiros sobre o bloco através de bombeamento (Silva, 1998).

O Sumário Mineral (2003) constatou que a produção de blocos de granito e mármore no Brasil está acima de seus 4.000.000ton/ano. Considerando que o RSRO corresponde, no mínimo, a $20 \%$ do volume do bloco, estima-se que o volume de resíduo gerado no Brasil é de cerca de 800.000ton/ano. O resíduo, geralmente, é descartado inadequadamente, afetando esteticamente a paisagem, além de acarretar custos de armazenamento e poluição ambiental.

Em caso de lançamento da lama abrasiva como rejeito diretamente nos rios, o assoreamento destes pode acontecer, poluindo suas águas e gerando impactos, como o comprometimento da sobrevivência animal e vegetal no ambiente.

Ao longo do tempo, várias pesquisas vêm sendo desenvolvidas, com vistas a proporcionar maior desempenho ao concreto, a partir da adição de resíduos, contribuindo, desta forma, para a preservação do meio ambiente (Moura et al., 2002; Moura et al., 2006; Almeida et al., 2005; Forner et al., 2005; Calmon et al., 1998; Calmon et al., 2005; Lameiras et al., 2005; Silva, 1998). Gonçalves (2000) avaliou a influência da adição do resíduo de corte de granito no concreto e concluiu que com até $20 \%$ de adição todas as propriedades do concreto foram melhoradas. O teor ótimo encontrado foi de 10\%.

Estudos desenvolvidos na Universidade Estadual de Feira de Santana/ BA (UEFS) avaliaram a viabilidade da utilização de resíduos gerados no processo de serragem dos blocos de rochas ornamentais (RSRO) na produção de blocos para alvenaria de vedação. Serão apresentados neste artigo, os resultados desse estudo.

\section{Produção de blocos em laboratório}

Os resultados apresentados referem-se ao resíduo coletado de uma empresa de beneficiamento de rochas ornamentais, localizada na cidade de
Feira de Santana, cujo processo de serragem se dá com polpa abrasiva. O estudo foi obtido em duas etapas. A primeira teve como principal objetivo a coleta e a caracterização do resíduo e demais materiais utilizados. A segunda compreendeu a definição de traços de referência e produção de blocos com e sem RSRO.

\section{Resíduo de serragem de rochas ornamentais (RSRO)}

Nesse estudo, foi utilizado um resíduo oriundo do processo de serragem de rochas que utiliza polpa abrasiva. Esse resíduo foi coletado de uma empresa beneficiadora de mármore e granito, transportado para os laboratórios da Universidade Estadual de Feira de Santana/Ba (UEFS) e estocado em baia, coberta adequadamente para que não houvesse contaminação. Em seguida, o material foi, então, caracterizado.

A secagem do resíduo foi feita em estufa, numa temperatura de $110^{\circ} \mathrm{C}$. Após a secagem, a amostra foi acondicionada em recipiente vedado para que não houvesse contato com umidade, nem contaminação.

Para a separação das partículas do resíduo, foi feito o destorroamento do mesmo em moinho de bolas horizontal, durante 3 minutos. Do ponto de vista das propriedades físicas do RSRO, foram avaliadas a massa específica e a massa unitária, obedecendo-se às prescrições normativas da NBR NM 23 (ABNT, 2001) e da NBR 7251 (ABNT, 1982). Também foi determinado o diâmetro médio do resíduo por granulometria a laser. Além disso, foi estabelecida a composição química do material.

O diâmetro médio da amostra é de $6,120 \mu \mathrm{m}$. Através desse diâmetro, pode-se verificar que o RSRO é um resíduo muito mais fino do que o cimento Portland. A Tabela 1 apresenta os demais resultados obtidos. 


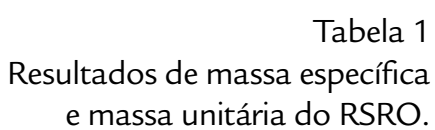

Os resultados da análise química mostram que, no RSROPA, há predominância de óxido de cálcio, havendo, ainda, uma significativa presença do óxido de ferro. Além disso, o material apresenta compostos químicos na forma tipicamente cristalina, como

\begin{tabular}{c|c|c|c|c|c|c|c|c|c|c|c}
\hline \multirow{2}{*}{$\begin{array}{c}\text { Massa } \\
\text { Específica } \\
\left(\mathrm{kg} / \mathrm{dm}^{3}\right)\end{array}$} & $\begin{array}{c}\text { Massa } \\
\text { Unitária } \\
\left(\mathrm{kg} / \mathrm{dm}^{3}\right)\end{array}$ & \multicolumn{10}{c|}{ Composição Química (\%) } \\
\cline { 5 - 12 } & $\mathrm{SiO}_{2}$ & $\mathrm{Al}_{2} \mathrm{O}_{3}$ & $\mathrm{MgO}$ & $\mathrm{K}_{2} \mathrm{O}$ & $\mathrm{TiO}_{2}$ & $\mathrm{Na}_{2} \mathrm{O}$ & $\mathrm{Fe}_{2} \mathrm{O}_{3}$ & $\mathrm{SO}_{4}$ & $\mathrm{CaO}$ & $\begin{array}{c}\text { Perda ao } \\
\text { fogo }\end{array}$ \\
\hline 2,74 & 1,01 & 5,893 & 1,231 & 0,397 & - & 0,35 & 0,298 & 9,06 & 0,40 & 79,01 & 0,211 \\
\hline
\end{tabular}

pode ser visualizado na Figura 1. Essa característica indica que o resíduo não possui propriedades aglomerantes ou pozolânicas.

Foram realizados ensaios de lixiviação e solubilização do RSRO. Nesses ensaios, os compostos lixiviados ou solubilizados não apresentaram concentração superior em relação aos limites estabelecidas pela NBR 10004 (ABNT, 2005) - Resíduos Sólidos - Classificação. Portanto, o resíduo é classificado como Classe III - Inerte.

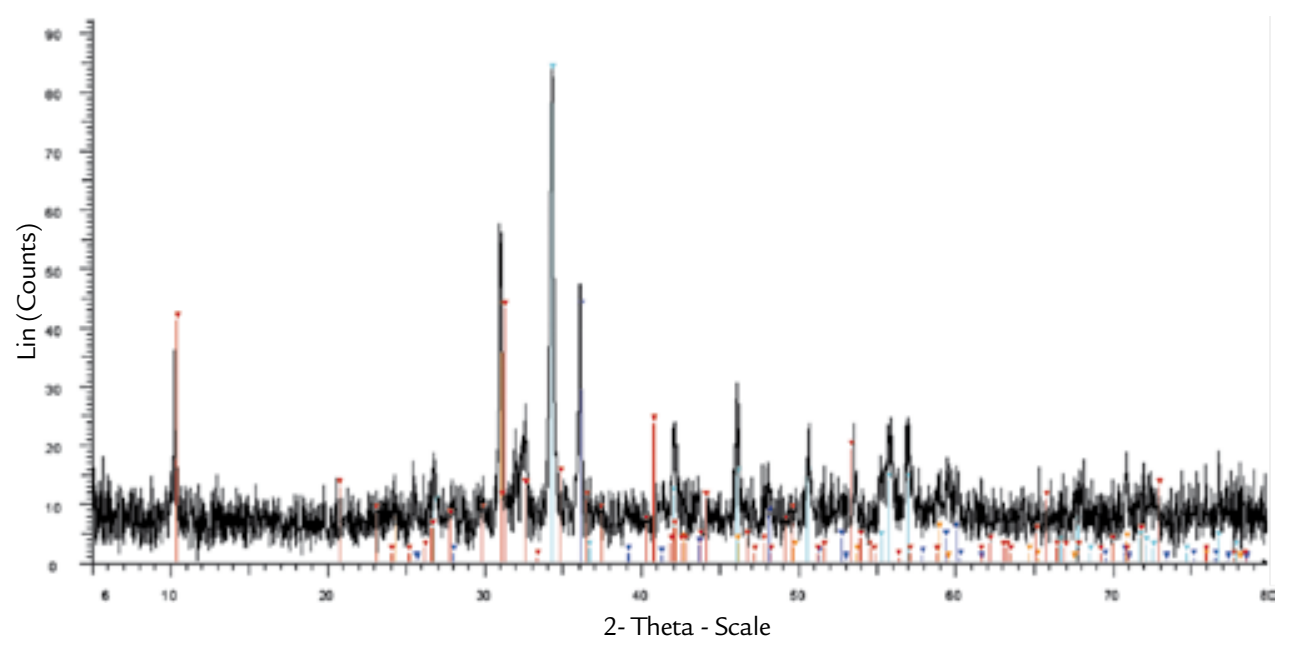

W RS ROHIS, Amostra 3 - File: ProjetoRS_ROHIS3.RAW

$\nabla 36-0426\left(^{*}\right)-\operatorname{CaMg}(\mathrm{CO} 3) 2$

$\nabla$ 05-0586 $\left(^{*}\right)$ - Calcite, syn - CaCO3

Figura $1 \quad \nabla 46-1045\left(^{*}\right)$ - Quartz, syn - SiO2

Difratograma de raios X do RSRO.

$\nabla$ 06-0263 (I) - Muscovite-2M 1, KAI2(Si3Al)O10(OH ,F)2

\section{Materiais e produção dos blocos}

Os materiais utilizados para pro-

\section{Materiais}

O cimento utilizado foi CP II F 32, por ser o tipo de cimento comumente utilizado na região de Feira de Santana. Os resultados atendem as exigências da

\section{Dosagem e produção dos blocos}

Para produção dos blocos, foi desenvolvido o traço de referência (sem utilização de RSRO), devendo o mesmo atender à resistência média à compressão de no mínimo $2,5 \mathrm{MPa}$ e absorção máxima de $10 \%$, de acordo com a NBR 7173 (ABNT, 1982). Com base em estudos anteriores para produção de blocos de vedação, com norma de especificação. Optou-se por se utilizar areia siltosa para produzir blocos de vedação. Também é comum, nessa região, o uso de finos oriundos da britagem

utilização de finos de britagem (Moura, 2004), definiu-se, como ponto de partida, iniciar a produção de blocos com o traço 1:8 (cimento:agregados, em massa).

A definição da proporção ideal de areia e finos de britagem foi feita com base no menor índice de vazios das misturas e tal proporção foi, determinada através do cimento, areia e finos de britagem.

de rochas graníticas e, por isso, eles foram utilizados nesse estudo. As características da areia e dos finos estão apresentadas na Tabela 2.

método MB 3324 (ABNT, 1990) - Solodeterminação do índice de vazios máximo de solos não coesivos. A proporção que alcançou o menor índice de vazios foi de $50 \%$ de areia siltosa e $50 \%$ de finos de britagem. Logo, considerando o melhor empacotamento da mistura, o traço unitário de referência foi 1:4,0:4,0:0,66 (cimento: 
areia siltosa: finos de britagem: água). As misturas foram feitas em betoneiras de eixo inclinado. Para cada traço, todos os materiais foram misturados a seco durante 90 segundos. Em seguida, foi adicionada a água e os materiais foram misturados por mais 90 segundos.

Os blocos foram produzidos numa vibro-prensa, sendo o tempo de vibração de 10 segundos. Após a prensagem, os blocos foram retirados da máquina e depositados na área de dosagem para posterior remoção dos paletes. As dimensões dos blocos de vedação foram de 200x100x400mm. Os blocos permaneceram cobertos com plástico durante 24

\begin{tabular}{|c|c|c|}
\hline Característica (Método de Ensaio) & $\begin{array}{l}\text { Areia } \\
\text { Siltosa }\end{array}$ & $\begin{array}{l}\text { Finos de } \\
\text { Britagem }\end{array}$ \\
\hline Dimensão Máxima Característica (mm) - NBR NM 248 (2003) & 2,4 & 4,8 \\
\hline Módulo de Finura - NBR NM 248 (2003) & 1,6 & 2,76 \\
\hline Massa Específica $\left(\mathrm{kg} / \mathrm{dm}^{3}\right)$ - NBR NM 52 (2003) & 2,6 & 2,587 \\
\hline Massa Unitária $\left(\mathrm{kg} / \mathrm{dm}^{3}\right)$ - NBR 7251 (1982) & 1,52 & 1,51 \\
\hline Material Pulverulento (\%) - NBR NM 46 (2003) & 10,6 & 10,8 \\
\hline Coeficiente de Inchamento - NBR 6467 (1987) & 1,29 & - \\
\hline Umidade Crítica (\%) - NBR 6467 (1987) & 2,25 & - \\
\hline Matéria Orgânica - NBR NM 49 (2001) & $\begin{array}{l}\text { Mais } \\
\text { Escura }\end{array}$ & - \\
\hline
\end{tabular}

\section{Resultados de resistência à compressão e absorção de água}

A resistência à compressão dos blocos de vedação, aos 7 e 28 dias, foi determinada de acordo com a NBR
7184 (ABNT, 1982) e a absorção de água foi determinada de acordo com NBR 12118 (ABNT, 1991). Na Tabela

\begin{tabular}{|c|c|c|c|c|c|c|c|c|c|c|c|c|c|}
\hline \multirow{8}{*}{ 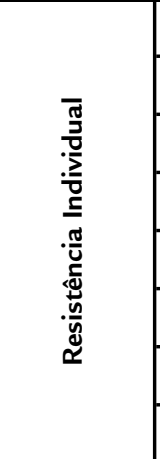 } & \multicolumn{2}{|c|}{ REF } & \multicolumn{2}{|c|}{$5 \%$} & \multicolumn{2}{|c|}{$10 \%$} & \multicolumn{2}{|c|}{$15 \%$} & \multirow{8}{*}{ 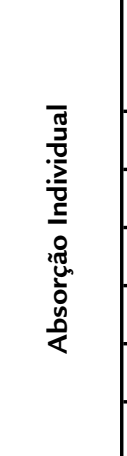 } & \multirow{2}{*}{ REF } & \multirow{2}{*}{$5 \%$} & \multirow{2}{*}{$10 \%$} & \multirow{2}{*}{$15 \%$} \\
\hline & $7 d$ & $28 d$ & $7 d$ & $28 d$ & $7 d$ & $28 \mathrm{~d}$ & $7 d$ & $28 \mathrm{~d}$ & & & & & \\
\hline & 2,1 & 3,0 & 2,0 & 2,4 & 2,2 & 2,6 & 2,5 & 3,3 & & 9,6 & 9,5 & 9,3 & 9,4 \\
\hline & 2,7 & 2,1 & 2,8 & 3,0 & 2,3 & 2,7 & 2,6 & 3,1 & & 9,8 & 9,7 & 10,0 & 9,7 \\
\hline & 1,6 & 3,2 & 2,4 & 2,9 & 2,3 & 2,6 & 2,0 & 2,9 & & 9,5 & 9,0 & 9,4 & 9,6 \\
\hline & 1,9 & 1,4 & 2,3 & 2,5 & 2,2 & 2,5 & 2,5 & 2,7 & & 9,9 & 9,7 & 9,2 & 9,6 \\
\hline & 2,2 & 3,0 & 2,6 & 2,4 & 2,2 & 3,4 & 2,3 & 2,9 & & 10,0 & 9,9 & 9,0 & 9,5 \\
\hline & 2,7 & 3,3 & 1,9 & 2,7 & 2,8 & 2,9 & 2,5 & 3,0 & & - & - & - & - \\
\hline $\mathrm{M}_{\text {édia }}(\mathrm{MPa})$ & 2,2 & 2,7 & 2,3 & 2,7 & 2,3 & 2,8 & 2,4 & 3,0 & $M_{\text {édia }}(\%)$ & 9,8 & 9,6 & 9,4 & 9,6 \\
\hline Sd. (MPa) & 0,4 & 0,8 & 0,3 & 0,3 & 0,2 & 0,3 & 0,2 & 0,2 & Sd. (\%) & 0,5 & 0,7 & 0,8 & 0,6 \\
\hline C.V. (\%) & 19,9 & 28,2 & 14,8 & 9,8 & 10,0 & 11,9 & 9,1 & 6,8 & C.V. (\%) & 4,8 & 8,2 & 8,8 & 6,8 \\
\hline
\end{tabular}

V-REF - vedação de referência; V5\%PA - vedação com 5\% de resíduo de serragem com polpa abrasiva; $\mathrm{V} 10 \% \mathrm{PA}$ - vedação com $10 \%$ de resíduo de serragem com polpa abrasiva; V15\%PA - vedação com $15 \%$ de resíduo de serragem com polpa abrasiva. Sd (MPa) Desvio-padrão. CV (\%) - Coeficiente de variação.

A influência do teor de substituição de cimento por RSRO e da idade dos corpos-de-prova, nos resultados de resistência à compressão dos blocos, foi verificada através da ANOVA (Análise de Variância). Os resultados dessa análise estão apresentados na Tabela 4. Esses resultados demonstram que, para os blocos produzidos, não há influência significativa do teor de substituição de cimento por RSRO. Por outro lado, há influência da idade de ruptura dos blocos. Observa-se que não há interação entre o teor de RSRO e a idade dos blocos.

Os resultados de absorção atendem ao limite estabelecido pela NBR 7173 horas para posterior cura por aspersão.

Após 24 horas da moldagem, os blocos foram retirados dos paletes e teve início a cura, por aspersão, durante 3 dias. Após esse período, os blocos foram mantidos em área coberta dos laboratórios até a data de capeamento para determinação da resistência e da absorção de água.

Tabela 2

Características da areia e dos finos de britagem usados no estudo.

3 estão apresentados os resultados obtidos nos dois ensaios.

Tabela 3

Resultados de resistência à compressão e absorção de água dos blocos de vedação.

(ABNT, 1982), que é de, no máximo, $10 \%$. Na Figura 2, apresentam-se os gráficos de resistência e de absorção relativos, em percentual, dos blocos produzidos com diferentes teores de RSRO, para a idade de 28 dias.

Apesar de os blocos com 15\% de RSRO apresentarem um aumento de 
cerca de $11 \%$ na resistência média, aos 28 dias, em relação aos blocos de referência, no conjunto de resultados essa diferença não foi considerada significativa. Logo, a substituição de cimento por

Tabela 4

Resultados da ANOVA para a resistência à compressão axial dos blocos de vedação com diferentes teores de RSRO.

Figura 2

Resistência à compressão e absorção relativa dos blocos de vedação, produzidos com diferentes teores de RSRO. até $15 \%$ de RSROPA é compatível para produção de blocos de vedação.

A absorção média dos blocos com até $15 \%$ de RSRO é menor do que a absorção média dos blocos de referên- cia. Os blocos com diferentes teores de RSRO apresentaram desempenho, quanto à absorção, coerente com o desempenho quanto à resistência à compressão.

\begin{tabular}{c|c|c|c|c|c}
\hline Fator & GDL & MQ & $F_{\text {cal }}$ & $F_{0,05}$ & Significância \\
\hline $\begin{array}{c}\text { A - teor de } \\
\text { substituição }\end{array}$ & 3 & 0,148 & 0,99 & 2,84 & NS \\
\hline B - idade & 1 & 2,475 & 16,52 & 4,08 & S \\
\hline AB & 3 & 0,036 & 0,239 & 2,84 & NS \\
\hline Erro & 40 & 0,150 & - & - & - \\
\hline
\end{tabular}

GDL - Graus de Liberdade; MQ - Média Quadrada; Fcal - Valor calculado de F; F0,05 - Valor tabelado de F para o nível de significância de 5\%; S - Significativo; NS - Não Significativo.
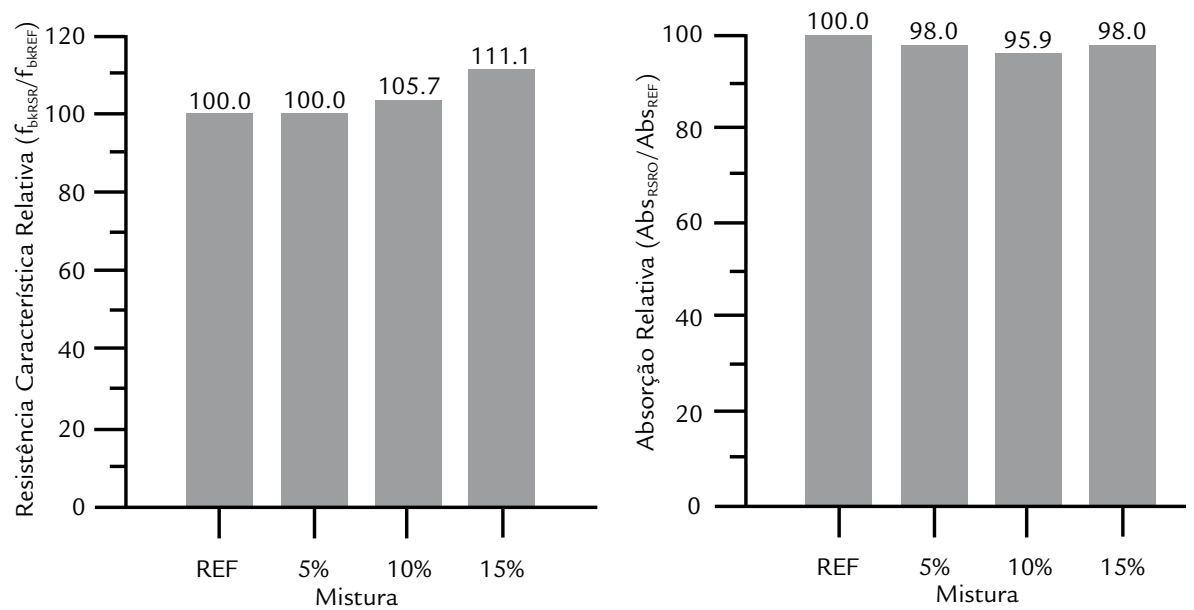

\section{Produção de blocos de vedação em uma fábrica de pré-moldados}

A verificação da influência da utilização de RSRO, no processo de produção de uma fábrica, foi viabilizada através de uma empresa de Feira de Santana/Bahia, tendo sido produzidos 200 blocos. A empresa utiliza máquina do tipo pneumática para fabricação dos blocos, conforme ilustra a Figura3a. Optou-se pela fabricação de blocos de vedação, mantendo-se todos os critérios que a empresa comumente utiliza. O traço utilizado em volume foi convertido em massa, sendo o traço de referência: 1 : 3,0: 13,0: 1,31 (cimento: areia fina: finos de britagem: água). O resíduo utilizado para os experimentos na fábrica foi o mesmo dos blocos produzidos em laboratório (RSRO), mantendo-se, ainda, os mesmos teores de substituição da massa de cimento $(5,10$ e $15 \%)$.

Os blocos foram curados com aspersão de água durante 3 dias (Figura 3b). Após esse período, os blocos foram transportados para os laboratórios da Universidade Estadual de Feira de Santana. Os blocos foram avaliados quanto à resistência à compressão aos 7 e 28 dias. Na Tabela 5, estão apresentados os resultados de resistência à compressão dos blocos. Os resultados de resistência relativa, aos 28 dias, estão apresentados na Figura 4.

Observa-se que a resistência média dos blocos com 5\% de RSRO foi superior em $5 \%$ à resistência dos blocos de referência. A resistência média dos blocos com $10 \%$ de resíduo foi igual à dos blocos de referência. Por outro lado, os blocos com $15 \%$ de RSROPA apresentaram uma redução de $10 \%$ na resistência média, em relação aos blocos de referência.

A influência do resíduo nos resultados de resistência dos blocos de vedação produzidos na fábrica foi semelhante à influência nos resultados de resistência dos blocos produzidos nos laboratórios. Exceto para o teor de $15 \%$ de RSROPA, os blocos produzidos no laboratório apresentaram resistência $11 \%$ superior a dos blocos referência, enquanto que, na fábrica, os blocos com $15 \%$ de RSROPA apresentaram resistência $10 \%$ inferior à dos blocos de referência.

Também foi feito um estudo comparativo de custos com base na produção dos blocos em fábrica, considerando apenas os custos de material. Na Tabela 6 , estão apresentados os resultados obtidos. A partir desses resultados, foi obtido o custo por unidade de resistência para cada mistura, que está apresentado na Figura 4.

Verifica-se que, para os blocos de vedação produzidos em fábrica, o custo referente aos materiais por $\mathrm{MPa}$ dos blocos com 5\% e 10\% de RSRO é menor do que o custo por $\mathrm{MPa}$ dos blocos de referência. Entretanto o custo por $\mathrm{MPa}$ dos blocos com $15 \%$ de RSRO é superior ao dos blocos de referência. Portanto pode-se dizer que é viável a substituição de até $10 \%$ da massa de cimento pelo resíduo, para este uso. Há que se considerar os ganhos ambientais decorrentes da substituição do cimento por RSRO. 

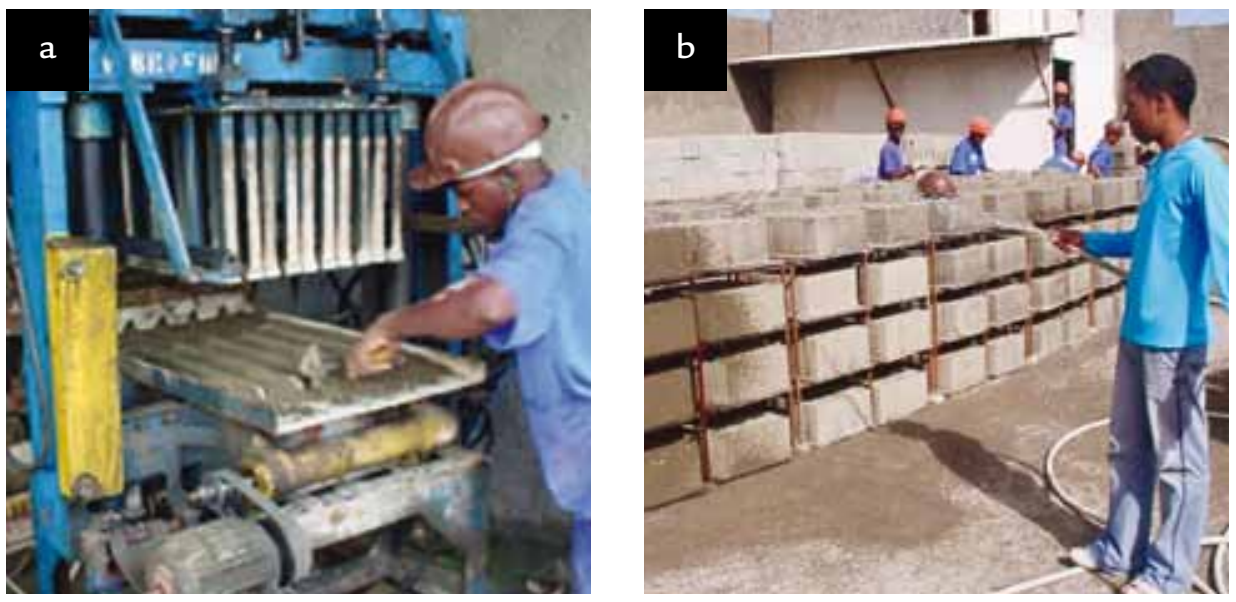

Figura 3

Produção dos blocos em uma empresa de pré-moldados:
a) Aspecto da prensa utilizada;
b) Cura dos blocos por aspersão.

\begin{tabular}{c|c|c|c|c|c|c|c|c}
\hline \multirow{4}{*}{} & \multicolumn{2}{|c|}{ REF } & \multicolumn{2}{c|}{$5 \%$} & \multicolumn{2}{c|}{$10 \%$} & \multicolumn{2}{c}{$15 \%$} \\
\cline { 2 - 9 } & $7 \mathrm{~d}$ & $28 \mathrm{~d}$ & $7 \mathrm{~d}$ & $28 \mathrm{~d}$ & $7 \mathrm{~d}$ & $28 \mathrm{~d}$ & $7 \mathrm{~d}$ & $28 \mathrm{~d}$ \\
\cline { 2 - 9 } & 3,1 & 4,2 & 3,5 & 3,7 & 3,5 & 3,9 & 3,3 & 4,3 \\
\cline { 2 - 9 } $\begin{array}{c}\text { Resistência } \\
\text { Individual }\end{array}$ & 2,1 & 4,2 & 4,3 & 4,7 & 3,5 & 4,0 & 3,5 & 3,1 \\
\cline { 2 - 9 } & 2,4 & 3,6 & 3,3 & 4,5 & 3,2 & 4,3 & 2,9 & 4,1 \\
\cline { 2 - 9 } & 1,9 & 4,3 & 3,2 & 4,8 & 3,2 & 4,1 & 2,6 & 3,2 \\
\cline { 2 - 9 } & 2,8 & 4,6 & 3,5 & 4,0 & 3,0 & 3,6 & 3,4 & 3,9 \\
\cline { 2 - 9 } & 2,2 & 3,3 & 3,2 & 3,7 & 3,4 & 3,8 & 2,4 & 3,2 \\
\hline \multirow{2}{*}{$M_{\text {édia }}(\mathrm{Pa})$} & 2,4 & 4,0 & 3,5 & 4,2 & 3,3 & 4,0 & 3,0 & 3,6 \\
\hline Sd. (MPa) & 0,5 & 0,5 & 0,4 & 0,5 & 0,2 & 0,2 & 0,5 & 0,5 \\
\hline C.V. (\%) & 18,8 & 12,0 & 11,8 & 11,7 & 6,1 & 6,1 & 15,0 & 14,5 \\
\hline
\end{tabular}

Tabela 5

Resultados de resistência à compressão dos blocos produzidos na fábrica de pré-moldados.
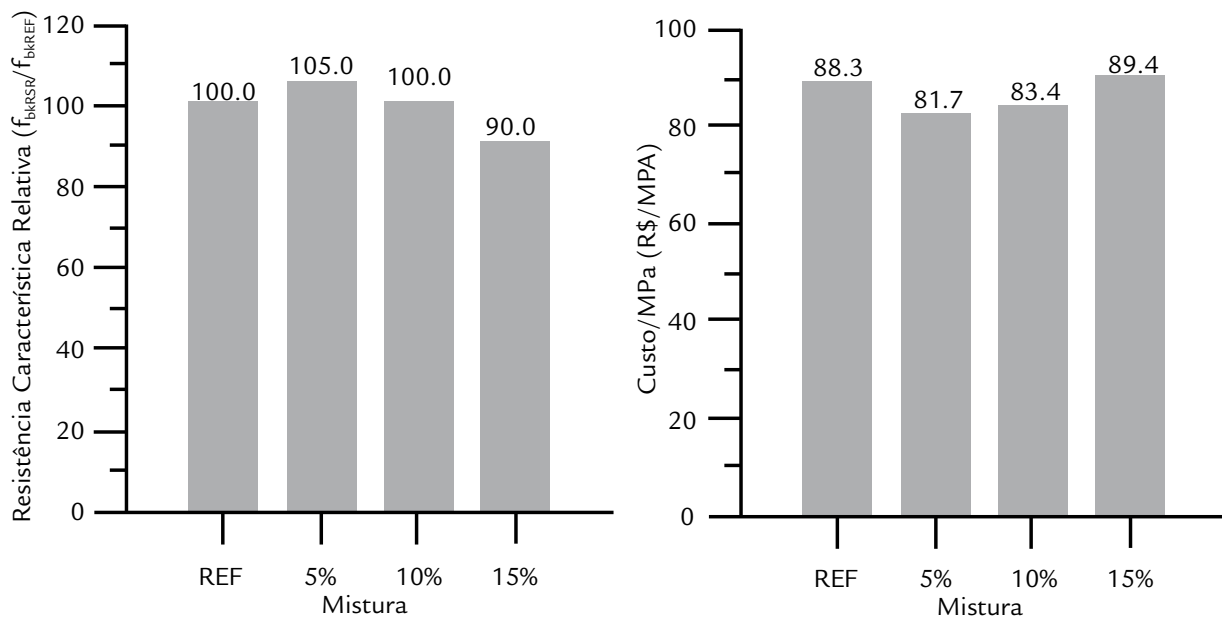

\begin{tabular}{|c|c|c|c|c|c|c|c|}
\hline \multirow[b]{2}{*}{ Mistura } & \multicolumn{3}{|c|}{ Quantidade de materiais } & \multicolumn{3}{|c|}{ Custo por material ( $R \$)$} & \multirow[b]{2}{*}{$\begin{array}{c}\text { Custo } \\
\text { Total (R\$) }\end{array}$} \\
\hline & $\begin{array}{c}\text { Cimento } \\
\text { (kg) }\end{array}$ & $\begin{array}{l}\text { Areia } \\
\left(\mathrm{m}^{3}\right)\end{array}$ & $\begin{array}{c}\text { Finos de } \\
\text { britagem } \\
\left(\mathrm{m}^{3}\right)\end{array}$ & Cimento & Areia & $\begin{array}{l}\text { Finos de } \\
\text { britagem }\end{array}$ & \\
\hline REF & 571 & 1,4 & 5,5 & 213,00 & 30,00 & 110,00 & 353,00 \\
\hline 5\%RSRO & 542 & 1,4 & 5,5 & 203,00 & 30,00 & 110,00 & 343,00 \\
\hline $10 \%$ RSRO & 514 & 1,4 & 5,5 & 192,70 & 30,00 & 110,00 & 332,70 \\
\hline $15 \%$ RSRO & 485 & 1,4 & 5,5 & 181,88 & 30,00 & 110,00 & 321,88 \\
\hline
\end{tabular}

Figura 4

Avaliação dos blocos produzidos na fábrica: a) Resistência à compressão relativa; b) Comparativo de custo por unidade de resistência à compressão.

Tabela 6

Comparativo de custos para produção dos blocos de vedação incorporando RSRO. 


\section{Conclusões}

A reciclagem é considerada como uma alternativa para o problema de destinação final adequada para os resíduos, sendo também essencial para a redução do impacto ambiental, provocado pelo crescente consumo de recursos naturais e pelo descarte inadequado desses resíduos.

O RSRO estudado é, predominantemente, composto por óxido de cálcio, com cerca de $9 \%$ de óxido de ferro, apresentando estrutura cristalina. $\mathrm{O}$ diâmetro médio é de $6,12 \mu \mathrm{m}$, sendo menor que o diâmetro do cimento Portland.

\section{Agradecimentos}

Os autores agradecem ao apoio da

\section{Referências Bibliográficas}

Nos blocos produzidos em laboratório, não houve diferença significativa entre a resistência à compressão dos blocos com RSRO e do bloco de referência (sem resíduo). Todos os resultados de absorção dos blocos atenderam ao limite estabelecido pela NBR 7173 (ABNT, 1982). A absorção média dos blocos com até 15\% de RSRO foi menor do que a absorção média dos blocos de referência.

Quanto aos blocos produzidos em fábrica, a resistência à compressão média com utilização de $5 \%$ e $10 \%$ de RSRO foi superior à resistência de referência. Os blocos com $15 \%$ de RSRO apresentaram uma redução de $10 \%$ na resistência média, em relação aos blocos de referência. A apropriação do custo dos blocos de vedação mostrou que é viável a substituição de até $10 \%$ da massa de cimento pelo RSRO. Cabe destacar, ainda, os ganhos ambientais decorrentes da substituição do cimento por RSRO, tanto no que se refere à destinação adequada do resíduo, quanto na minimização de geração de $\mathrm{CO} 2$ e na exploração dos recursos naturais.

FINEP pelo financiamento desta pesquisa.

ABNT - ASSOCIAÇÃO BRASILEIRA DE NORMAS TÉCNICAS. NBR 10004 - Resíduos Sólidos - Classificação. Rio de Janeiro, 2005.

. NBR 12118: Bloco vazado de concreto simples para alvenaria - determinação da absorção de água, do teor de umidade e da área líquida - método de ensaio. Rio de Janeiro, 1991.

. NBR 6467: Agregados - determinação do inchamento de agregado miúdo - método de ensaio. Rio de Janeiro, 1987.

. NBR 7173: Blocos vazados de concreto simples para alvenaria sem função estrutural. Rio de Janeiro, 1982.

.NBR 7184: Blocos vazados de concreto simples para alvenaria - determinação da resistência à compressão - método de ensaio. Rio de Janeiro, 1992.

NBR 7251: Determinação da massa unitária. Rio de Janeiro, 1982.

. NBR NM 23: Cimento Portland e outros materiais em pó: determinação da massa específica. Rio de Janeiro, 2001.

. NBR NM 46: Agregados - Determinação do material fino que passa através da peneira $75 \mu m$, por lavagem. Rio de Janeiro, 2003.

. NBR NM 49: Agregado fino - determinação de impurezas orgânicas. Rio de Janeiro, 2001.

NBR NM 52: Agregado miúdo - determinação de massa específica e massa específica aparente. Rio de Janeiro, 2003.

NBR NM 248: Agregados - determinação da composição granulométrica. Rio de Janeiro, 2003.

ALMEIDA, N., BRANCO, F., SANTOS, J. R. Recycling of stone slurry in industrial activities: application to concrete mixtures. Building and Environment. London: Elsevier, 2005. 10p. (no prelo).

CALMON, J. L., TRISTÃO, F. A., SOUZA, F. L. S., SILVA, S. C., MATTOS, F.V. Aproveitamento do resíduo de corte de granito para a produção de tijolos de solo-cimento. In: ENCONTRO NACIONAL DE TECNOLOGIA DO AMBIENTE CONSTRUÍDO - ENTAC98, 7. Anais... Florianópolis - SC, 1998.

CALMON, J. L., MORATTI, M., SOUZA, F. L. S., CENCI, D. S. Concreto auto-adensável utilizando resíduo de serragem de rochas ornamentais como filer. In: CONGRESSO BRASILEIRO DO CONCRETO - CBC2005, 47. Anais... Recife, 2005. Volume V - Inovações Tecnológicas para o Concreto. Trabalho 47CBC341. p.V453-466.

CHIODI FILHO, C. Situação do setor de rochas ornamentais e de revestimento no Brasil mercados interno e externo. IN: SIMPÓSIO DE ROCHAS ORNAMENTAIS DO NORDESTE, 5. Anais... Recife: Deminas, DAU, PPGEMinas, SBG, SINDIPEDRAS, 2005. 28p.

FORNER, M., LINTZ, R.C.C., BOZZA, J.L. Estudo da resistência à compressão de concretos com resíduos das indústrias de lavra e de polimento de rochas. In: CONGRESSO BRASILEIRO DO CONCRETO - CBC2005, 47. Anais... Recife, 2005. Volume V - Inovações 
Tecnológicas para o Concreto. Trabalho 47CBC335. p.V767-772.

GONÇALVES, J.P. Utilização do resíduo de corte de granito (RCG) como adição para a produção de concretos. Porto Alegre: PPGEC/UFRGS - Escola de Engenharia, Universidade Federal do Rio Grande do Sul, 2000. 135p. (Dissertação de Mestrado).

GUERRA, E. A. Apoio do MCT ao setor de rochas ornamentais e revestimentos. In: SIMPÓSIO DE ROCHAS ORNAMENTAIS DO NORDESTE, 5. Recife: Deminas, DAU, PPGEMinas, SBG, SINDIPEDRAS. Anais... Recife, 2005. 12p.

LAMEIRAS, R. M., TENÓRIO, J. J. L., LIMA, L.A. Avaliação do potencial de utilização do resíduo do beneficiamento de chapas de granito (RBCG) em concretos. In: CONGRESSO BRASILEIRO DO CONCRETO - CBC2005, 47. Anais... Recife, 2005. Volume V - Inovações Tecnológicas para o Concreto. Trabalho 47CBC0331. p.V317-332.

MOURA, C. B., PAGNUSSAT, D. T., TUTIKIAN, B. F., MASUERO, Â. B., DAL MOLIN, D. C.C. Avaliação de concretos auto-adensáveis dosados pelo Método Tutikian incorporando resíduos de serragem de mármores e granitos. In: CONGRESSO BRASILEIRO DO CONCRETO, 48. Anais... Rio de Janeiro: IBRACON, 2006. CD-ROM.

MOURA, W. A. Aproveitamento do resíduo de agregado graúdo natural (pó de pedra) como agregado miúdo para argamassa e concreto para peças pré-moldadas. Feira de Santana: Universidade Estadual de Feira de Santana, 2004. 47p. (Monografia para mudança de classe de professor).

MOURA, W. A., GONÇALVES, J. P., LEITE, R. da S. Utilização do resíduo de corte de mármore e granito em argamassas de revestimento e confecção de lajotas para piso. Sitientibus - Revista da Universidade Estadual de Feira de Santana, Feira de Santana, n.26, p.49-61, jan./jun. 2002.

SILVA, S. C. da. Caracterização física, química e ambiental do resíduo de granito. Potencialidades para fabricação de argamassas e de tijolos de solo-cimento. Vitória: Universidade Federal do Espírito Santo, 1998. 148p. (Dissertação de Mestrado).

Artigo recebido em 28 de novembro de 2010. Aprovado em 09 de fevereiro de 2011. 